\title{
Postoperative audiovestibular assessment of obstructive sleep apnea patients
}

\author{
Hesham Saad Kouzo', Mohamed Aziz Mohamed Talaat', Ahmed Yassin Bahgat ${ }^{2}$, \\ Hazem Ahmed Mousa Zamel ${ }^{3}$ and Mirhan Khamis Eldeeb ${ }^{1 *}$ (i)
}

\begin{abstract}
Background: In obstructive sleep apnea syndrome, the impact of hypoxia on different body systems is of utmost importance. Brainstem is greatly sensitive to the effects of hypoxia including auditory and vestibular nuclei. Our aim in the current study is to evaluate hypoxic effect of OSAS on the audiovestibular system using auditory brainstem response, cervical vestibular evoked myogenic potential, and video nystagmography and to determine whether this effect is reversible postoperatively.

Results: In OSAS patients, the mean absolute and interpeak latencies of ABR were significantly prolonged compared to controls and remained so postoperatively. No statistically significant difference between pre- and postoperative values was found. The differences in the mean latencies of P1 and N1 of the CVEMP responses between the two groups were insignificant. However, there was a significant difference in P1N1 amplitude. On the other hand, the difference in the mean amplitude of the P1N1 wave in the study group postoperatively was not significant. The VNG results included bilateral canal paresis in four, unilateral in two, and spontaneous nystagmus in two patients. Also, two patients showed pursuit abnormality and two had saccadic abnormality which did not improve postoperatively.
\end{abstract}

Conclusions: Patients with moderate to severe OSAS experience both auditory and vestibular deficits which do not reverse 3 months after corrective surgery.

Keywords: Obstructive sleep apnea syndrome, Auditory brainstem response, Vestibular-evoked myogenic potentials, Videonystagmography, Hypoxia

\section{Background}

Obstructive sleep apnea syndrome (OSAS) is defined as repetitive bouts of upper airway obstruction that take place during sleep, usually coupled with a drop in blood oxygen saturation. A distinctive pattern of snoring pattern is linked to this syndrome which includes loud snores or brief gasps, which alternate with periods of apnea which usually last from 20 to $30 \mathrm{~s}$ [1].

The degree of OSAS can be determined by several methods such as calculating the apnea-hypopnea index

\footnotetext{
* Correspondence: mirhan.eldeeb@alexmed.edu.eg

'Department of Otorhinolaryngology, Audio-vestibular Unit, Faculty of Medicine, Alexandria University, Al Sultan Hussein Street, Al Kartoom Square, Al Azareeta, Alexandria 21111, Egypt

Full list of author information is available at the end of the article
}

(AHI) that is the product of adding the number of apneas and hypopneas events during an hour of sleep, the amount of decrease in oxygen saturation during sleep, or the extent of the commonest related symptom, daytime somnolence. OSAS can be defined as an AHI of minimally 5 episodes/hour. A subject has mild OSAS if he/she has an AHI between five and 15 events/hour, moderate OSAS ranges from 15 to 30 events, and severe OSAS more than 30 events in an hour [2]. Hypopnea is defined as a reduction of airflow which ranges from 50 to $90 \%$ for no less than $10 \mathrm{~s}$ which causes oxygen desaturation of $4 \%$ [3].

OSAS can produce chronic hypoxia which might affect brainstem centers among which are respiratory, auditory, and vestibular centers. Studies confirm that

\section{Springer Open}

(c) The Author(s). 2020 Open Access This article is licensed under a Creative Commons Attribution 4.0 International License, which permits use, sharing, adaptation, distribution and reproduction in any medium or format, as long as you give appropriate credit to the original author(s) and the source, provide a link to the Creative Commons licence, and indicate if changes were made. The images or other third party material in this article are included in the article's Creative Commons licence, unless indicated otherwise in a credit line to the material. If material is not included in the article's Creative Commons licence and your intended use is not permitted by statutory regulation or exceeds the permitted use, you will need to obtain permission directly from the copyright holder. To view a copy of this licence, visit http://creativecommons.org/licenses/by/4.0/. 
regional blood flow drops in the brainstem of apneic patients and this would likely exacerbate the side effects of apnea on the auditory brainstem [4]. Chronic hypoxia might create a dysfunction in the brainstem centers leading to a change of auditory brainstem response $(\mathrm{ABR})$ traces and more deterioration of the sleep apnea because of injury to the respiratory centers, producing a vicious circle with additional undesirable impacts on the auditory system. This might explain why central apnea occurs in OSAS [5].

Few studies assess the impact of hypoxemia due to OSAS on ABR which have demonstrated delayed peak and interpeak latencies of ABR waves [6-9].

In addition, a small number of researchers have studied the impact of hypoxia in patients with OSAS on the vestibular system. One study, which recorded cervical vestibular, evoked myogenic potential (cVEMP) in OSAS patients, found the detection rate of the P1N1, N2P2, and P1N1, N2P2 amplitudes to be significantly different in patients when compared to norms [10]. Video nystagmography (VNG) responses were also recorded in two studies in OSAS subjects. In one study, there was bilateral vestibular weakness, unilateral vestibular weakness, increased latency of saccades, and change in the morphology of smooth-pursuit eye movements in study subjects when compared to controls [6]. Another study found spontaneous nystagmus, nystagmus after head shake, pursuit abnormalities, and detected bilateral low gain in patients [11].

There are two main treatment options for OSAS which are ventilation and surgery. Other treatment modalities include oral appliances and weight loss. To be efficient, the surgery must be precisely selected, performed, and proper procedures must be customized to the individual needs of the patient. The collapse pattern in each patient must be assessed before scheduling any type of surgery [12]. It is not known if treating OSAS will undo any damage secondary to chronic hypoxia.

Our aim in this study is to evaluate the hypoxic effect of OSAS on the audiovestibular system and to study the effect of surgical correction of OSAS on the audiovestibular system by functional assessment using ABR, cVEMP, and VNG.

\section{Methods}

\section{Study design}

This investigation was a prospective interventional study conducted between April 2017 and May 2018.

All subjects were also assessed by otoscopic examination, pure tone thresholds, tympanograms, and stapedial reflexes on the first visit to diagnose any otological pathologies. Patients with history of head trauma, malignancy, neurologic and psychiatric disorders, endocrine disorders, metabolic and cardiovascular disorders, and history of intake of drugs known to affect the lung functions and vascular reactivity, any middle or inner ear diseases (e.g., use of ototoxic drug therapy), or with previous diagnosis of neurotological disease (i.e., labyrinthine diseases, benign paroxysmal positional vertigo), simple snoring or mild OSAS and those unfit for general anesthesia were excluded from the study. The study protocol was accepted by the ethics committee. An informed consent was written by subjects included in the study.

Fifteen patients (30 ears) with a diagnosis of moderate to severe OSAS and an AHI more than 15 were included in the study. Ten age- and gender-matched controls (20 ears) without OSAS (AHI < 5) participated in the current study.

\section{Sleep study}

OSAS was diagnosed based on the results of a computerized polysomnogram system (64-channel Compumedics E series, Melbourne, Victoria, Australia) done overnight. The apnea-hypopnea index (AHI) was calculated in accordance with the American Academy of sleep medicine recommendations.

\section{Auditory brainstem response}

ABRs were accomplished using Smart EP version 5.00 (Intelligent Hearing Systems, 6860 SW 81st St, Miami, FL 33143, USA). The time window was $12 \mathrm{~ms}$, and the responses were band-pass filtered from 30 to $3000 \mathrm{~Hz}$. An acoustic click with a pulse duration of $0.1 \mathrm{~ms}$ was presented with alternating polarity to remove stimulus artifacts and cochlear microphonics in the traces. Stimulus rate was set to 21 clicks/s. The stimulus intensity was $80 \mathrm{~dB} \mathrm{nHL}$ to allow precise allocation of the peaks. The stimulus was delivered 1200 times per recording trial and no less than two trials/replications were harvested to allow clear identification of the response. The non-inverting electrode was located on the forehead, the inverting electrode was placed on the ipsilateral mastoid, and the ground was positioned on the contralateral mastoid. Latencies of the waves I, III, and V, alongside interpeak latencies of I-III, I-V, and III-V were calculated from the recordings.

\section{Cervical vestibular evoked myogenic potential}

Each subject sat in a chair. The subject's head was flexed about $30^{\circ}$ forward and turned $30^{\circ}$ to one side to harvest responses from the opposite side. The sternocleidomastoid muscle was chosen to record the VEMPs. The surface EMG activity was recorded by a Smart EP intelligent hearing systems version 5.00. Air conduction tone burst stimuli of $500 \mathrm{~Hz}$ frequency and condensation polarity were monaurally presented to the tested ear at 
an intensity of $105 \mathrm{dBnHL}$. The stimuli were Blackman gated 2-1-2 cycle delivered at a rate of 5 cycles/s and one channel ipsilateral recording was harvested. The noninverting electrode was positioned on the upper one third of the ipsilateral sternocleidomastoid, the inverting electrode on the sternoclavicular junction, and the ground electrode was placed on the forehead. As a minimum, two runs were recorded to ensure reproducibility and 150 sweeps were collected for each run, averaged, and amplified with an analysis time of $50 \mathrm{~ms}$. The bandpass filter ranged between 5 and $750 \mathrm{~Hz}$.

\section{Videonystagmography}

Eye movements were recorded by using a video-based system Otometrics ICS Chartr 200 (GN Otometrics, Taastrup, Denmark). Saccades and smooth pursuit were measured. Any spontaneous and/or positional nystagmus was recorded. Bithermal caloric testing was also done with suppression fixation. Accuracy, velocity, and latency of saccades were analyzed. Symmetry and gain were tested in smooth pursuit. For the caloric stimulation, water of 44 to $30^{\circ} \mathrm{C}$ temperatures was used with a 40-s period of stimulation. First, the right ear was irrigated with $44{ }^{\circ} \mathrm{C}$ water; followed by the left ear with $44{ }^{\circ} \mathrm{C}$ water; then the left ear with $30^{\circ} \mathrm{C}$ water; lastly, the right ear with $30^{\circ} \mathrm{C}$ water. Patients were given a period of $5 \mathrm{~min}$ between each of the irrigations. The subject was supine while flexing the head $30^{\circ}$ upward [13].. Twenty seconds later, the head was tilted to the same side to remove water from the canal. After that, the head was turned back to the neutral position for caloric testing. The maximum slow-phase velocity of the resulting nystagmus was marked after each irrigation. The values of slow-phase velocity were inserted in the Jongkee's formula to determine hyporeflexia:

$\%$ Caloric paresis $=100 \times[(\mathrm{LC}+\mathrm{LW})-(\mathrm{RC}+\mathrm{RW}) /(\mathrm{LC}+\mathrm{LW}+\mathrm{RC}+\mathrm{RW})]$.

Where $\mathrm{LC}=$ left cold, $\mathrm{LW}=$ left warm, $\mathrm{RC}=$ right cold, and RW = right warm. It was considered abnormal if the value was $>20 \%$.

\section{Statistical analysis}

The statistical analysis was done using the SPSS software for Windows version 20.0 (IBM, Armonk, NY). The chisquare test was used to measure categorical variables. The student $t$ test was used to analyze the significant differences between groups and the paired $t$ test was used to analyze the significant differences in the patients before and after intervention.

\section{Results}

There was no neurotologic pathology, history of vertigo, or hearing loss in the controls. In spite of the fact that all individuals had bilateral within normal serviceable hearing up to $2000 \mathrm{~Hz}$, most individuals had mild to moderate high-frequency sensorineural hearing loss (SNHL). OSAS patients showed a higher average of pure tone thresholds compared to controls who displayed no improvement postoperatively. However, this difference exhibited no statistical significance $(p=0.051)$. The mean age was $47.53 \pm 10.93$ for cases and $43.0 \pm 11.15$ for controls respectively. Difference in age and gender displayed no statistical significance between the two studied groups $(p=0.328, p=1.000)$ respectively. AHI value was $43.93 \pm 28.51$ in the OSAS group while it was $2.90 \pm 0.88$ in controls.

\section{Auditory brainstem response}

In OSAS patients, the mean peak latencies of waves I, III, and V and interpeak latencies I-III, I-V, and III-V were significantly increased in comparison to controls and remained so postoperatively (Table 1). Absolute latencies of waves III and V exhibited higher significance $(p<0.001)$ in the OSAS patients $(3.91 \pm 0.20)$ and $(5.90$ $\pm 0.35)$ respectively in comparison to controls (3.70 \pm $0.17)$ and (5.60 \pm 0.13$)$ respectively. Comparing the peak and interpeak $A B R$ latencies in patients postoperatively revealed no statistical significance between pre- and postoperative latencies, although slight improvement was detected (Table 1).

\section{Vestibular-evoked myogenic potential}

For the VEMP responses, the detection rate of the P1N1 wave was $80 \%$ for the OSAS group (24 ears), which stayed the same postoperatively, and $100 \%$ for controls (20 ears) (Fig. 1). This difference exhibited no statistical significance $(p=0.069)$. For the OSAS group, $\mathrm{P} 1$ and $\mathrm{N} 1$ mean latencies were $16.26 \pm 4.37$ and $21.19 \pm 3.67 \mathrm{~ms}$ respectively preoperatively and $14.94 \pm 4.22$ and $20.51 \pm$ $4.07 \mathrm{~ms}$ respectively postoperatively. For norms, these values were $14.45 \pm 0.99$ and $19.63 \pm 1.21 \mathrm{~ms}$ (Table 2). The differences were insignificant. Conversely, for the OSAS group, the mean P1N1 amplitude was $15.75 \pm$ $4.74 \mu \mathrm{V}$ preoperatively, $15.89 \pm 4.05 \mu \mathrm{V}$ postoperatively while it was $21.37 \pm 5.36 \mu \mathrm{V}$ in the control group. The difference in P1N1 amplitude between the two studied groups displayed statistical significance $(p=0.001)$ (Table 2). Yet, the mean amplitude of the P1N1 wave in the OSAS group after surgery was not significantly different from controls $(p=0.867)$.

\section{Videonystagmography}

Based on VNG results, in the OSAS group, there were four patients who exhibited bilateral canal paresis (26.7\%), two patients $(13.3 \%)$ who had unilateral canal paresis, and two patients (13.3\%) who displayed spontaneous nystagmus. Two patients (13.3\%) in the OSAS 
Table 1 Comparison between the two studied groups and the effect of treatment on OSAS group according to ABR

\begin{tabular}{|c|c|c|c|c|}
\hline & \multirow[t]{2}{*}{ ABR } & \multicolumn{2}{|l|}{ Cases $(n=30)$} & \multirow{2}{*}{$\begin{array}{l}\text { Control } \\
(n=20)\end{array}$} \\
\hline & & Pre-treatment & Post-treatment & \\
\hline \multirow[t]{15}{*}{ Absolute latency } & Wave I & & & \\
\hline & Min.-max. & $1.37-2.14$ & $1.34-1.99$ & $0.88-1.97$ \\
\hline & Mean \pm SD & $1.72 \pm 0.19$ & $1.68 \pm 0.16$ & $1.56 \pm 0.23$ \\
\hline & Median & 1.74 & 1.7 & 1.59 \\
\hline & Sig. bet. grps. & \multicolumn{2}{|c|}{$p_{1}=0.391, p_{2}=0.009^{*}, p_{3}=0.031^{*}$} & \\
\hline & Wave III & & & \\
\hline & Min.-Max. & $3.60-4.28$ & $3.36-4.17$ & $3.38-3.97$ \\
\hline & Mean \pm SD & $3.91 \pm 0.20$ & $3.83 \pm 0.24$ & $3.70 \pm 0.17$ \\
\hline & Median & 3.92 & 3.87 & 3.67 \\
\hline & Sig. bet. grps. & \multicolumn{2}{|c|}{$p_{1}=0.131, p_{2}<0.001^{*}, p_{3}=0.029^{*}$} & \\
\hline & Wave V & & & \\
\hline & Min.-max. & $5.27-6.52$ & $5.26-6.22$ & $5.41-5.88$ \\
\hline & Mean \pm SD. & $5.90 \pm 0.35$ & $5.80 \pm 0.22$ & $5.60 \pm 0.13$ \\
\hline & Median & 5.91 & 5.84 & 5.56 \\
\hline & Sig. bet. grps. & \multicolumn{2}{|c|}{$p_{1}=0.235, p_{2}<0.001^{*}, p_{3}<0.001^{*}$} & \\
\hline \multirow[t]{15}{*}{ Interpeak latency } & $\mathrm{I}-\mathrm{V}$ & & & \\
\hline & Min.-max. & $3.60-4.77$ & $3.43-4.87$ & $3.52-4.86$ \\
\hline & Mean \pm SD. & $4.29 \pm 0.34$ & $4.25 \pm 0.41$ & $4.02 \pm 0.32$ \\
\hline & Median & 4.30 & 4.20 & 3.92 \\
\hline & Sig. bet. grps. & \multicolumn{2}{|c|}{$p_{1}=0.646, p_{2}=0.007^{*}, p_{3}=0.001^{*}$} & \\
\hline & I-III & & & \\
\hline & Min.-max. & $1.83-2.63$ & $1.73-2.92$ & $1.47-2.57$ \\
\hline & Mean \pm SD. & $2.21 \pm 0.20$ & $2.15 \pm 0.21$ & $1.98 \pm 0.27$ \\
\hline & Median & 2.25 & 2.15 & 1.99 \\
\hline & Sig. bet. grps. & \multicolumn{2}{|c|}{$p_{1}=0.249, p_{2}=0.034^{*}, p_{3}=0.020^{*}$} & \\
\hline & III-V & & & \\
\hline & Min.-max. & $1.73-2.92$ & $1.74-2.32$ & $0.83-2.88$ \\
\hline & Mean \pm SD. & $2.14 \pm 0.26$ & $2.10 \pm 0.14$ & $1.89 \pm 0.51$ \\
\hline & Median & 2.14 & 2.08 & 1.84 \\
\hline & Sig. bet. grps. & \multicolumn{2}{|c|}{$p_{1}=0.416, p_{2}=0.048^{*}, p_{3}=0.031^{*}$} & \\
\hline
\end{tabular}

Sig. bet. grps significance between groups, $p_{1} p$ value for paired $t$ test for comparing between cases pre and post treatment, $p_{2} p$ value for Student's $t$ test for comparing between cases at pre-treatment and control, $p_{3} p$ value for Student's $t$ test for comparing between cases at post-treatment and control *Statistically significant at $p \leq 0.05$

group showed pursuit abnormality and had bilateral low gain and the same two patients (13.3\%) had saccadic deficits with diminished velocity and prolonged latency > $200 \mathrm{~ms}$. These findings stayed the same postoperatively. In the controls, one patient (10\%) experienced unilateral canal paresis and one subject (10\%) showed decreased gain in saccade and increased latency in pursuit. There was no positional nystagmus in both studied groups. Spontaneous nystagmus, oculomotor findings, and caloric paresis displayed no significant difference among the two studied groups $(p \leq 0.05)$ (Table 3).

\section{Discussion}

OSAS is defined as repeated attacks of obstruction in the upper respiratory tract presenting as cessation of breathing (apnea) or airflow diminution (hypopnea) during sleep, deep snoring, and daytime drowsiness. OSAS affects several body systems and is becoming more frequently recognized because of its considerable side effects on systems such as the central nervous system, the cardiovascular system, and the cognitive system for instance memory impairments, inattention, defective executive functioning, and incoordination of fine motor 


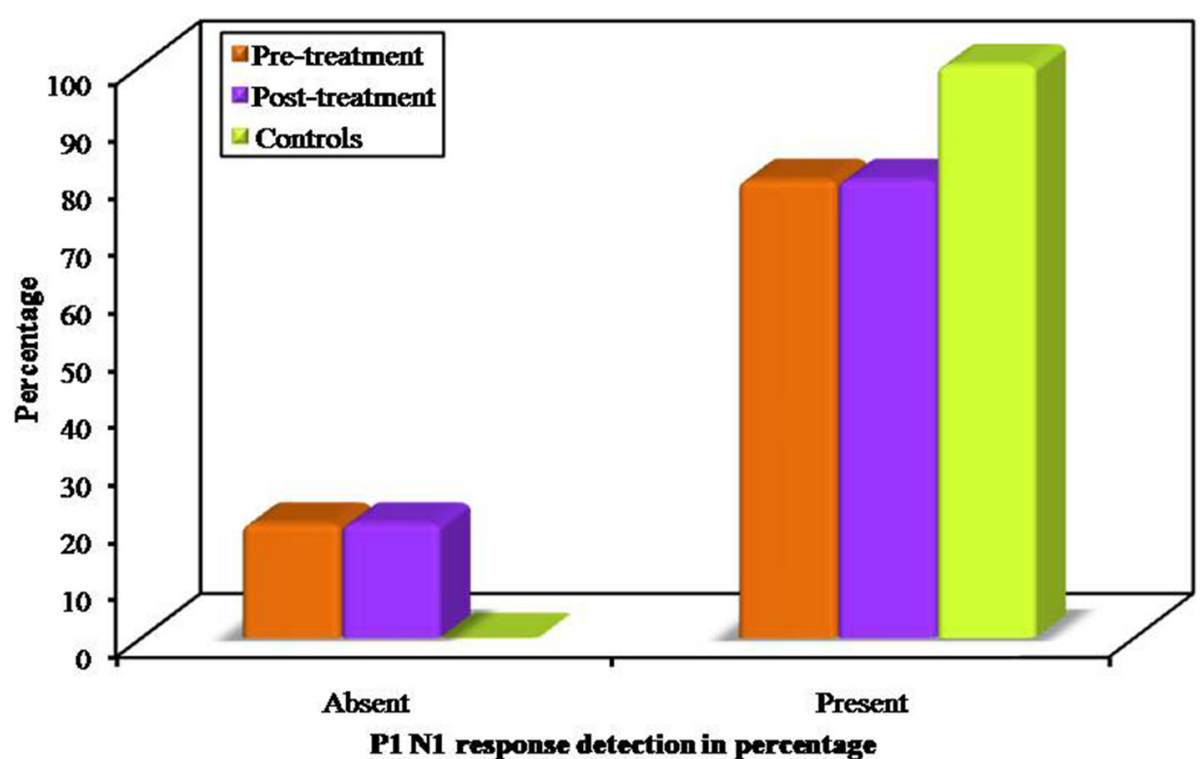

Fig. 1 Comparison between the two studied groups and the effect of treatment on OSAS group according to P1N1 response detection in percentage

Table 2 Comparison between the two studied groups and the effect of treatment on OSAS group according to CVEMP

\begin{tabular}{|c|c|c|c|c|c|c|}
\hline \multirow[t]{3}{*}{ cVEMP } & \multicolumn{4}{|c|}{ Cases $(n=30)$} & \multirow{2}{*}{\multicolumn{2}{|c|}{ Control $(n=20)$}} \\
\hline & \multicolumn{2}{|c|}{ Pre-treatment } & \multicolumn{2}{|c|}{ Post-treatment } & & \\
\hline & No. & $\%$ & No. & $\%$ & No. & $\%$ \\
\hline \multicolumn{7}{|c|}{ P1N1 response detection in percentage } \\
\hline Absent & 6 & 20.0 & 6 & 20.0 & 0 & 0.0 \\
\hline Present & 24 & 80.0 & 24 & 80.0 & 20 & 100.0 \\
\hline Sig. bet. grps. & \multicolumn{6}{|c|}{${ }^{\mathrm{McN}} p_{1}=1.000,{ }^{x} p_{2}=0.069,{ }^{x} p_{3} 0.069$} \\
\hline P1 latency & $(n=24)$ & & \multicolumn{2}{|l|}{$(n=24)$} & \multicolumn{2}{|l|}{$(n=20)$} \\
\hline Min.-max. & $8.64-23.60$ & & \multicolumn{2}{|l|}{$8.27-24.80$} & \multicolumn{2}{|l|}{$11.16-15.10$} \\
\hline Mean $\pm S D$ & $16.26 \pm 4.37$ & & \multicolumn{2}{|l|}{$14.94 \pm 4.22$} & \multicolumn{2}{|l|}{$14.45 \pm 0.99$} \\
\hline Median & 18.12 & & \multicolumn{2}{|l|}{13.62} & \multicolumn{2}{|l|}{14.91} \\
\hline Sig. bet. grps. & \multicolumn{6}{|c|}{${ }^{\mathrm{t} p} p_{1}=0.130,{ }^{\mathrm{t}} p_{2}=0.060,{ }^{\mathrm{t}} p_{3}=0.174$} \\
\hline N1 latency & $(n=24)$ & & \multicolumn{2}{|l|}{$(n=24)$} & \multicolumn{2}{|l|}{$(n=20)$} \\
\hline Min.-max. & $10.24-24.50$ & & \multicolumn{2}{|l|}{$9.52-27.07$} & \multicolumn{2}{|l|}{$17.31-21.20$} \\
\hline Mean \pm SD. & $21.19 \pm 3.67$ & & \multicolumn{2}{|l|}{$20.51 \pm 4.07$} & \multicolumn{2}{|l|}{$19.63 \pm 1.21$} \\
\hline Median & 22.40 & & \multicolumn{2}{|l|}{19.96} & \multicolumn{2}{|l|}{19.60} \\
\hline Sig. bet. grps. & \multicolumn{6}{|c|}{${ }^{\mathrm{tp}} p_{1}=0.558,{ }^{\mathrm{t}} p_{2}=0.066,{ }^{\mathrm{t}} p_{3}=0.334$} \\
\hline P1-N1 amplitude & $(n=24)$ & & \multicolumn{2}{|l|}{$(n=24)$} & \multicolumn{2}{|l|}{$(n=20)$} \\
\hline Min.-max. & $7.68-24.62$ & & \multicolumn{2}{|l|}{$8.76-24.91$} & \multicolumn{2}{|l|}{$9.45-31.17$} \\
\hline Mean \pm SD & $15.75 \pm 4.74$ & & \multicolumn{2}{|l|}{$15.89 \pm 4.05$} & \multicolumn{2}{|l|}{$21.37 \pm 5.36$} \\
\hline Median & 16.84 & & \multicolumn{2}{|l|}{16.23} & \multicolumn{2}{|l|}{21.40} \\
\hline Sig. bet. grps. & \multicolumn{6}{|c|}{${ }^{\mathrm{t}} p_{1}=0.867,{ }^{\mathrm{t}} p_{2}=0.001^{*},{ }^{\mathrm{t}} p_{3}<0.001^{*}$} \\
\hline
\end{tabular}

Sig. bet. grps significance between groups, $t_{\mathrm{p}}$ paired $t$ test, $t$ Student's $t$ test, McN McNemar test, $\mathrm{X}^{2}$ chi-square test, $p_{1} p$ value for comparing between cases preand post-treatment, $p_{2} p$ value for comparing between cases at pre-treatment and control. $p_{3} p$ value for comparing between cases at post-treatment and control *Statistically significant at $p \leq 0.05$ 
Table 3 Videonystagmography findings of the study groups

\begin{tabular}{lllll}
\hline & $\begin{array}{l}\text { Spontaneous } \\
\text { nystagmus }\end{array}$ & Caloric test & Unilateral paresis & $\begin{array}{l}\text { Oculomotor } \\
\text { abnormality }\end{array}$ \\
\cline { 3 - 5 } OSAS group & $2(13.3 \%)$ & Bilateral paresis & $2(13.3 \%)$ & $2(13.3 \%)$ \\
Control group & 0 & 0 & $1(10 \%)$ & $1(10 \%)$ \\
$\boldsymbol{p}$ value & 0.140 & 1.000 & 0.236 & 1.000 \\
\hline
\end{tabular}

$t$ Student's $t$ test

*Statistically significant at $p \leq 0.05$

skills. Repeated episodes of drop in oxygen saturation then rise of its saturation in OSAS trigger the inflammatory cascade, deoxygenation, and impaired endothelial cell function [14]. Insufficient oxygenation causes damage of the vasa nervorum, and persistent hypoxia gives rise to neural loss in the central neurons and injury to peripheral nerves [15]. Preceding studies point out that hypoxia influences neural cells in the brainstem in addition to the forebrain [16].

This study was carried out to assess the hypoxic effect of OSAS on auditory and vestibular brainstem pathways and to measure the impact of surgical correction of OSAS on audiovestibular function.

This aim was accomplished by comparing the findings of ABR, VEMP, and VNG at three points in time: difference between cases before the operation and 3 months postoperatively; difference between cases preoperatively and controls; and difference between cases 3 months postoperatively and controls.

Although all OSAS subjects in the current study showed bilateral within normal serviceable hearing up to $2000 \mathrm{~Hz}$, most individuals had mild to moderate highfrequency SNHL and the average of pure tone thresholds of the OSAS subjects was more than controls. The impact of OSAS on auditory functions has only seldom been reported. Hoffstein et al. [17] reported that snoring showed no connection to age-related hearing loss. Also, Hwang et al. [18] could not prove a considerable contribution of OSAS to peripheral auditory dysfunction using linear regression. Additionally, Mutlu and colleagues found that all their test subjects had normal hearing thresholds $(<25 \mathrm{~dB} \mathrm{HL})$ at 500 through $4000 \mathrm{~Hz}$ [10]. On the contrary, Sardesai et al. found that bed partners of snorers could show unilateral, noise-induced hearing impairment while snorers themselves had no normal hearing [19]. In favor of a connection, Fisher et al. [20] showed that patients who suffered from sudden hearing loss had OSAS more frequently than their controls. Also, Cao et al. [21] demonstrated that the average of pure tone thresholds and high-frequency thresholds in individuals with OSAS were diminished in comparison to the auditory thresholds of age-matched controls. Therefore, it seems that OSAS, but not snoring, is coupled with peripheral hearing loss. This inconsistency in the previous research might be due to differences in the age of inclusion or number of subjects, plus the degree of OSAS and/or hearing thresholds among studies. This might also be linked to the inclusion criteria of some studies as Mutlu and colleagues [10] who excluded patients older than 60 years, those with hearing loss, and cases who have a body mass index more than 40 .

In this study, we noticed obvious auditory abnormalities in OSAS subjects despite the absence of other auditory hazards, signifying that the hypoxemia in OSAS could pose a threat to the auditory system $[22,23]$. The prolonged peak and interpeak latencies of $A B R$ traces demonstrate a distorted conduction in the retrocochlear auditory neural substrates, mainly in rostral brainstem at the inferior colliculus [8, 9]. El-Kady et al. have established that local blood supply diminishes in the brainstem of apneic patients and this might aggravate the hypoxic effects of apnea on the brainstem substrates of the auditory pathwa $y[4]$. The long-term hypoxia of the brainstem could produce dysfunction of its centers leading to a change of ABR traces and more deterioration of the sleep apnea as a consequence of damage to respiratory centers, producing a vicious circle together with negative effects on the auditory system. This might shed light on the central apnea in patients with OSAS [5]. Dziewas et al. [24] demonstrated how the repeated intermittent hypoxia can be regarded as a possible contributor to dysfunction of the peripheral sensory nerves. They postulated that the treatment of OSAS might give rise to an enhanced functionality of these nerves [25].

The possible contribution of the brainstem in the pathogenesis of OSAS is generally unknown. ABR has been used by numerous researchers to assess the brainstem function. Contradictory findings were shown concerning the results of ABR in OSAS patients' normal traces in some studies [26-29] and abnormal in others [30-32] have been recorded. Muchnik et al. [8] demonstrated that OSAS patients had considerable delay in the mean latencies of peaks I, III, and V, and in the interpeak latencies I-III and I-V as opposed to norms. Snyderman et al. [31] examined 23 sleep apnea patients and showed that patients with central apnea $(n=6)$ demonstrated increased latency of wave $\mathrm{V}$ and interpeak latency I-V, even though only four patients had unilateral increased latencies. Seven out of 11 OSAS patients also demonstrated increased latency of wave $\mathrm{V}$ and interpeak 
latency I-V. In Stockard et al. [30], four patients with central apnea $(n=8)$ demonstrated impaired ABR tracks while those with obstructive or mixed sleep apnea $(n=$ 20) showed normal tracks. Severe OSAS patients in Matsumura et al. [33] showed a higher prevalence of abnormalities in wave $\mathrm{V}$ and interpeak $\mathrm{I}-\mathrm{V}$ (33\%) as opposed to $(10 \%)$ in control subjects. However, this was not significant. Gallina [6] reported an increase in I-V wave interpeak latency in $36.5 \%$ of OSAS patients and in 4 control subjects. Casale et al. [15] showed abnormalities in III-V and I-V intervals in severe OSAS subjects. The same authors also showed increased latencies of waves I, III, V, and III-V, and I-V intervals in patients with severe degree of OSAS compared to norms. Mosko and colleagues [28] reported that waves I through V latencies was comparable to norms in six OSAS patients during sleep and also when they were awake. Karnaze et al. [27] reported that interpeak interval I-V was abnormally prolonged in only one out of 18 patients who had obstructive, central, mixed apneas when compared to controls. Other researchers have shown normal ABR findings in both obstructive and central apneas [26-29].

A possible justification for the ABR results could be the intermittent recurring hypoxic events which take place continuously at night for years. ABR is a common technique used to examine the function of the auditory system in animals subjected to hypoxic episodes. Many studies emphasized that only a threshold shift occurred when the arterial level of oxygen dropped beneath 30 $\mathrm{mmHg}$ (or beneath about $45 \%$ arterial oxygen saturation) [9]. Mosko et al. [28] who tested six OSAS subjects failed to exhibit any effect of the diminution in arterial oxygen saturation on the ABR tracing, even when saturation dropped down to $45 \%$. In Carlile et al. [22], six healthy controls were subjected to mild hypoxia for a period of $20 \mathrm{~min}$, which caused a decrease of the mean blood oxygen saturation to $75-85 \%$ with subsequent substantial increase in wave $\mathrm{V}$ latency. The authors postulated that these findings emphasized the high sensitivity of the auditory system is to oxygen deprivation.

It has been reported that chronic hypersomnolence might result in brainstem dysfunction, leading to abnormalities in ABR traces. Beckerman et al. [34] studied four infants suffering from Ondine's syndrome and reported prolonged wave III latency and I-III interpeak latency. Reduction of the hypoxic and hypercarbic responses during sleep has been demonstrated in children who have this disease. This suggests impaired function of chemoreceptor nerve endings in the brainstem respiratory centers. The chemoreceptor neurons are located in the medulla near to the superior olivary complex, the supposed generator of wave III. Thus, chronic hypersomnolence may damage the respiratory centers and affect the nearby generator of wave III, although the pathophysiology is unclear.

Contrary to the results of this study with assessing the effect of corrective surgery of OSAS on ABR traces, one study [8] which compared ABR before and after uvulopalatoplasty and/or tracheotomy exhibited significant prolongation of wave III and interpeak I-III latencies in the preoperative patients, which significantly improved following surgery. The authors made the conclusion that the postoperative patients, particularly those who showed the best response to treatment of OSAS, exhibited better ABR findings. Consequently, untreated (preoperative) OSAS patients exhibit increased wave III and interpeak I-III latencies; they also emphasized that these abnormalities tend to improve with treatment of OSAS and, so, appear to be connected to the symptoms of the condition and not the cause of OSAS. This dissimilarity with the results of the current study may be attributable to the variability in the number of patients, and inclusion criteria where 79 patients were included who had normal hearing thresholds $(\leq 20 \mathrm{dBHL})$, age of the subjects was up to 55 years, and only males were recruited. Thirty-six out of the 79 patients had uvulopalatoplasty, and the ABR tracings before and 3 months after surgery were compared.

In this study, we noticed that the responses of P1N1 waves were comparable between OSAS patients and controls. However, the amplitude of P1N1 in OSAS subjects was statistically lower compared to the control group. Both P1 and N1 latencies and amplitude of P1N1 demonstrated minor improvement postoperatively. These results show a minor effect of hypoxia secondary to OSAS on the utricular function, examined by cVEMP, which does not reverse up to 3 months postoperatively. Mutlu et al. [10] reported similar results where P1N1 amplitude in severe OSAS subjects was reduced as opposed to controls. Analyzing our results, we suggest that the hypoxia in moderate and severe degrees of OSAS impairs the sacculocollic reflex within the brainstem and thus decreases the VEMP response. Yet, we were not able to explain the clinical significance of the results that in the moderate and severe OSAS subjects showed no major changes in latencies but the amplitudes were reduced. Based on our findings to assess brainstem insult in moderate to severe OSAS, cVEMP can be a diagnostic tool. Still, this study has one drawback, the sample size. Operative treatment failed to improve the reduction in cVEMP amplitude which can be attributable to the small duration following treatment or the small sample size.

Similar results in caloric testing to the ones in this study were detected in a study by Gallina and colleagues [6] with bilateral hyporeflexia found in $37.9 \%$ and unilateral hyporeflexia in $13.7 \%$ of the mild-to-moderate OSAS group. On the other hand, $56.2 \%$ showed bilateral 
hyporeflexia and $18.7 \%$ had unilateral hyporeflexia in severe OSAS group. Pursuit abnormality was detected in $6.8 \%$ of patients in the mild-to-moderate OSAS group and $18.7 \%$ in the severe OSAS group. Another study [11] found a comparable set of abnormalities where $16 \%$ had spontaneous nystagmus, $56 \%$ had canal weakness, and $4 \%$ had bilateral low gain in pursuit. However, the oculomotor deficits in our subjects could have been caused by the relatively older age of the study group compared to the literature.

The compromise of vestibular nuclei might be an indicator for abnormal respiratory nuclear activity considering the anatomical proximity of this center. Damage to the vestibular nuclei might be shown by a change of the slow and rapid phase velocities of eye movements. VNG allows quantitative and qualitative assessment of both peripheral and central vestibular functions, giving us the chance to collect precise information about the alterations observed in OSAS. The posterior labyrinth has been found to be highly vulnerable to the hypoxic state as observed by the high rate of vestibular reflex deficits in caloric testing. Sleep deprivation secondary to OSAS may affect postural stability owing to diminished adaptation ability and periods of inattention. Sleep deprivation has been found to influence the activity of the right temporoparietal cortex that is also responsible for VOR control [35]. An inconsequential deficit of the central vestibular connections is demonstrated by the minor abnormalities seen in the oculomotor tests of the study group which could as well be attributed to agerelated hearing impairment. These brainstem and cerebellar substrates are supposed to regulate eye movements and ocular reflexes.

The aforementioned results demonstrate an obvious disagreement between the absence of subjective symptoms of vestibular dysfunction as dizziness or vertigo compared to the objective results of VNG which exhibited variations in $10 / 15$ patients. A potential justification is that the caloric test findings, in these patients, could be affected by other factors for instance mental alertness, drowsiness, or periods of inattention caused by OSAS with subsequent suppression of caloric nystagmus, leading to bilateral vestibular hypofunction. However, it is appealing to postulate that long-term hypoxia in OSAS causes a progressive decline in vestibular function. When hypoxia causes asymmetry in the peripheral vestibular system, the central vestibular connections compensate this disequilibrium. Our results may also point out that central vestibular connections are more defiant to hypoxia. Consequently, a unilateral peripheral vestibular hypofunction may be centrally corrected and thus balance can be restored.
Again the lack of improvement in VNG results following surgery might be accredited to the short duration following surgery or limited sample size.

\section{Conclusion}

OSAS patients with moderate to severe disease show audiovestibular deficits that do not improve up to 3 months postoperatively.

\section{Abbreviations \\ ABR: Auditory brainstem response; AHI: Apnea-hypopnea index; cVEMP: Cervical vestibular evoked myogenic potential; dB HL: Decibel hearing level; EMG: Electromyography; OSAS: Obstructive sleep apnea; SNHL: Sensorineural hearing loss; VNG: Videonystagmography; \\ VOR: Vestibulo-ocular reflex}

\section{Acknowledgements}

Not applicable

\section{Authors' contributions}

$\mathrm{HZ}$ has participated in data acquisition and interpretations and drafting of the manuscript. HK, MT, and AB diagnosed the cases and made the concept and design of the work, and made major contributions in writing the manuscript. $\mathrm{HZ}$ and ME participated in the analysis of data and interpretation of the results. MK was a major contributor in writing the manuscript and made an intelligible revision of the text. The authors read and approved the final manuscript.

Funding

None.

\section{Availability of data and materials}

The datasets used and/or analyzed during the current study are available from the corresponding author on reasonable request.

\section{Ethics approval and consent to participate}

The current research was approved by the Institutional Ethical Committee of the Faculty of Medicine, Alexandria University (EC Ref No: 020970). Also, written informed consents were obtained from all patients to participate in the research.

Consent for publication

Written informed consents for publication were obtained from all patients.

Competing interests

The authors declare that they have no competing interests.

\section{Author details}

${ }^{1}$ Department of Otorhinolaryngology, Audio-vestibular Unit, Faculty of Medicine, Alexandria University, Al Sultan Hussein Street, Al Kartoom Square, Al Azareeta, Alexandria 21111, Egypt. ²Department of Otorhinolaryngology, Head And Neck Surgery Unit, Faculty of Medicine, Alexandria University, Alexandria, Egypt. ${ }^{3}$ Department of Otorhinolaryngology, Audio-vestibular Unit, Alexandria Police Hospital, Alexandria, Egypt.

Received: 23 October 2020 Accepted: 19 November 2020

Published online: 01 December 2020

\section{References}

1. American Academy of Sleep M (2005) The international classification of sleep disorders: diagnostic and coding manual. 2nd ed. American Academy of Sleep Medicine, Westchester 30-40

2. Boyd SB, Upender R, Walters AS, Goodpaster RL, Stanley JJ, Wang L et al (2016) Effective apnea-hypopnea index ("Effective AHI"): a new measure of effectiveness for positive airway pressure therapy. Sleep 39(11):1961-1972

3. Kushida CA (2007) Obstructive sleep apnea: pathophysiology, comorbidities, and consequences. Informa Healthcare, London 
4. El-Kady MA, Durrant JD, Tawfik S, Abdel-Ghany S, Moussa AM (2006) Study of auditory function in patients with chronic obstructive pulmonary diseases. Hear Res 212(1-2):109-116

5. Miyamoto T, Miyamoto M, Takekawa H, Kubo J, Hirata K, Katayama S (2001) A comparison of middle latency auditory-evoked response in obstructive sleep apnea syndrome before and after treatment. Psychiatry Clin Neurosci 55(3):251-252

6. Gallina S, Dispenza F, Kulamarva G, Riggio F, Speciale R (2010) Obstructive sleep apnoea syndrome (OSAS): effects on the vestibular system. Acta Otorhinolaryngol Ital 30(6):281-284

7. Liu Y, Li Z, Sun Z, Jiang W, Feng X (2005) The features of auditory brainstem response in patients with obstructive sleep apnea-hypopnea syndrome. Lin Chuang Er Bi Yan Hou Ke Za Zhi 19(15):678-679

8. Muchnik C, Rubel Y, Zohar Y, Hildesheimer M (1995) Auditory brainstem response in obstructive sleep apnea patients. J Basic Clin Physiol Pharmacol 6(2):139-148

9. Sohmer H, Freeman S, Schmuel M (1989) ABR threshold is a function of blood oxygen level. Hear Res 40(1-2):87-91

10. Mutlu M, Bayir O, Yuceege MB, Karagoz T, Firat H, Ozdek A et al (2014) Vestibular evoked myogenic potential responses in obstructive sleep apnea syndrome. Eur Arch Otorhinolaryngol 272(11):3137-3141

11. Kayabasi S, Iriz A, Cayonu M, Cengiz B, Acar A, Boynuegri S et al (2014) Vestibular functions were found to be impaired in patients with moderateto-severe obstructive sleep apnea. Laryngoscope 125(5):1244-1248

12. Vicini C, Dallan I, Canzi P, Frassineti S, La Pietra MG, Montevecchi F (2010) Transoral robotic tongue base resection in obstructive sleep apnoeahypopnoea syndrome: a preliminary report. ORL J Otorhinolaryngol Relat Spec 72(1):22-27

13. Bhansali SA, Honrubia V (1999) Current status of electronystagmography testing. Otolaryngol Head Neck Surg 120(3):419-426

14. Budhiraja R, Parthasarathy S, Quan SF (2007) Endothelial dysfunction in obstructive sleep apnea. J Clin Sleep Med 3(4):409-415

15. Casale M, Vesperini E, Potena M, Pappacena M, Bressi F, Baptista PJ et al (2012) Is obstructive sleep apnea syndrome a risk factor for auditory pathway? Sleep Breath 16(2):413-417

16. Zhang JH, Fung SJ, Xi M, Sampogna S, Chase MH (2010) Apnea produces neuronal degeneration in the pons and medulla of guinea pigs. Neurobiol Dis 40(1):251-264

17. Hoffstein V, Haight J, Cole P, Zamel N (1999) Does snoring contribute to presbycusis? Am J Respir Crit Care Med 159(4 Pt 1):1351-1354

18. Hwang JH, Chen JC, Hsu CJ, Liu TC (2011) Association of obstructive sleep apnea and auditory dysfunctions in older subjects. Otolaryngol Head Neck Surg 144(1):114-119

19. Sardesai MG, Tan AK, Fitzpatrick M (2003) Noise-induced hearing loss in snorers and their bed partners. J Otolaryngol 32(3):141-145

20. Fischer Y, Yakinthou A, Mann WJ (2003) Prevalence of obstructive sleep apnea syndrome (OSA) in patients with sudden hearing loss. A pilot study. HNO 51(6):462-466

21. Cao Y, Luo Z, Tao Z, Zhu S, Li J, Shu J et al (2006) Analysis of the hearing of patients with obstructive sleep apnea-hypopnea syndrome. Lin Chuang Er Bi Yan Hou Ke Za Zhi 20(1):1-3

22. Carlile S, Paterson DJ (1992) The effects of chronic hypoxia on human auditory system sensitivity. Aviat Space Environ Med 63(12):1093-1097

23. Mazurek B, Haupt H, Georgiewa P, Klapp BF, Reisshauer A (2006) A model of peripherally developing hearing loss and tinnitus based on the role of hypoxia and ischemia. Med Hypotheses 67(4):892-899

24. Dziewas R, Schilling M, Engel P, Boentert M, Hor H, Okegwo A et al (2007) Treatment for obstructive sleep apnoea: effect on peripheral nerve function. J Neurol Neurosurg Psychiatry 78(3):295-297

25. Pfeiffer $G$, Kunze K, Bruch M, Kutzner M, Ladurner G, Malin JP et al (1990) Polyneuropathy associated with chronic hypoxaemia: prevalence in patients with chronic obstructive pulmonary disease. J Neurol 237(4): 230-233

26. Peled R, Pratt $H$, Scharf B, Lavie P (1983) Auditory brainstem evoked potentials during sleep apnea. Neurology 33(4):419-423

27. Karnaze D, Gott P, Mitchell F, Loftin J (1984) Brainstem auditory evoked potentials are normal in idiopathic sleep apnea. Ann Neurol 15(4):406

28. Mosko SS, Pierce S, Holowach J, Sassin JF (1981) Normal brain stem auditory evoked potentials recorded in sleep apneics during waking and as a function of arterial oxygen saturation during sleep. Electroencephalogr Clin Neurophysiol 51(5):477-482
29. Verma NP, Kapen S, King SD, Koshorek GJ (1987) Bimodality electrophysiologic evaluation of brainstem in sleep apnea syndrome. Neurology 37(6):1036-1039

30. Stockard JJ (1982) Brainstem auditory evoked potentials in adult and infant sleep apnea syndromes, including sudden infant death syndrome and nearmiss for sudden infant death. Ann N Y Acad Sci 388:443-465

31. Snyderman NL, Johnson JT, Moller M, Thearle PB (1982) Brainstem evoked potentials in adult sleep apnea. Ann Otol Rhinol Laryngol 91 (6 Pt 1):597598

32. Wetmore SJ, Henderson C, Doshier NW, Milligan LB (1988) Auditory brainstem response in obstructive sleep apnea. Laryngoscope 98(5):499-501

33. Matsumura E, Matas CG, FCL M, Pedreno RM, Lorenzi-Filho G, SGG S et al (2016) Evaluation of peripheral auditory pathways and brainstem in obstructive sleep apnea. Braz J Otorhinolaryngol S1808-8694(16):3023330236

34. Beckerman R, Meltzer J, Sola A, Dunn D, Wegmann M (1986) Brain-stem auditory response in Ondine's syndrome. Arch Neurol 43(7):698-701

35. Quarck G, Ventre J, Etard O, Denise P (2006) Total sleep deprivation can increase vestibulo-ocular responses. J Sleep Res 15(4):369-375

\section{Publisher's Note}

Springer Nature remains neutral with regard to jurisdictional claims in published maps and institutional affiliations.

\section{Submit your manuscript to a SpringerOpen ${ }^{\circ}$ journal and benefit from:}

- Convenient online submission

- Rigorous peer review

- Open access: articles freely available online

High visibility within the field

- Retaining the copyright to your article

Submit your next manuscript at $>$ springeropen.com 